\title{
Detecting Cooling Effect of Landscape Composition and Configuration: An Urban Heat Island Study on Hangzhou
}

\author{
Hao Hou ${ }^{\text {a, }}$, Ronald C. Estoque ${ }^{\text {b }}$ \\ ${ }^{a}$ Institute of Remote Sensing and Earth Sciences, Hangzhou Normal University, Yuhangtang Road No.2318, Hangzhou 311121, \\ China.houhao@hznu.edu.cn. \\ ${ }^{b}$ Center for Social and Environmental Systems Research, National Institute for Environmental Studies, Onogawa \\ 16-2, Tsukuba City, Ibaraki 305-0053, Japan.rons2k@yahoo.co.uk. \\ * Corresponding author
}

Keywords: Land cover type; Land surface temperature; Urban forest; Urban water bodies; Sustainable cities.

\begin{abstract}
:
Global warming is widely regarded as one of the most critical environmental issue in the 21 st century. It is known to exacerbate urban heat island effects, a phenomenon that could affect the livability of cities and the lives and comfort of more than half of the world population who are now living in urban areas. The issue on how to mitigate the impacts of this phenomenon and help urban dwellers adapt to it, has been, and continues to be, an important topic in the context of landscape design and urban planning. This study sought to examine the cooling effects of different land cover types from the perspectives of landscape composition and configuration. Landsat-8 OLI/TIRS data was employed to derive both landscape composition and land surface temperature (Figure 1). The objectives of this study are to: (1) detect the spatial pattern of LST in Hangzhou; (2) examine the cooling effect of land cover resources; and (3) understand the correlation between LST and land cover from the perspectives of composition and configuration. Its goal is to reflect on optimal landscape patterns from the perspective of mitigating UHI effects and building more comfortable and livable urban environments. Various spatial and statistical approaches, including urban-rural gradient, grid-based, landscape metrics, and scatter plot, were employed to analyze the derived land cover and land surface temperature (LST) maps. An urban-rural gradient analysis was performed to examine the difference in LST between the urban and rural areas. First, we created a multiple ring buffer zone from the city center of Hangzhou with a distance interval of $1 \mathrm{~km}$. Second, we determined the mean LST and the density of all the land cover types (LCTs) in each ring buffer zone. Finally, the results were plotted along the urban-rural gradient for analysis (Figure 2). The results showed that forest and water were the cooling land cover types in Hangzhou during daytime. The heat core in Hangzhou was situated close to the central business district and the variance in LST in urban and rural recorded at $2.94{ }^{\circ} \mathrm{C}$. The correlation of forest density with mean LST could be detected in both large $(690 \mathrm{~m})$ and small $(210 \mathrm{~m})$ grids, whereas the correlation of water density with mean LST was only observed in small grids. In general, forest with high aggregation and complex shape behave best in cooling LST while huge and complete water bodies had better cooling effect than scattered water patches. Besides, the minimum cooling scale of forest and water were $150 \mathrm{~m}$ and $120 \mathrm{~m}$, respectively. The findings were considered valuable for urban planners to spatially and architecturally build and arrange the cooling land cover resources, eventually to fulfill the Chinese government's new plan of building "livable cities".
\end{abstract}




\section{$\operatorname{LST}\left({ }^{\circ} \mathrm{C}\right)$}
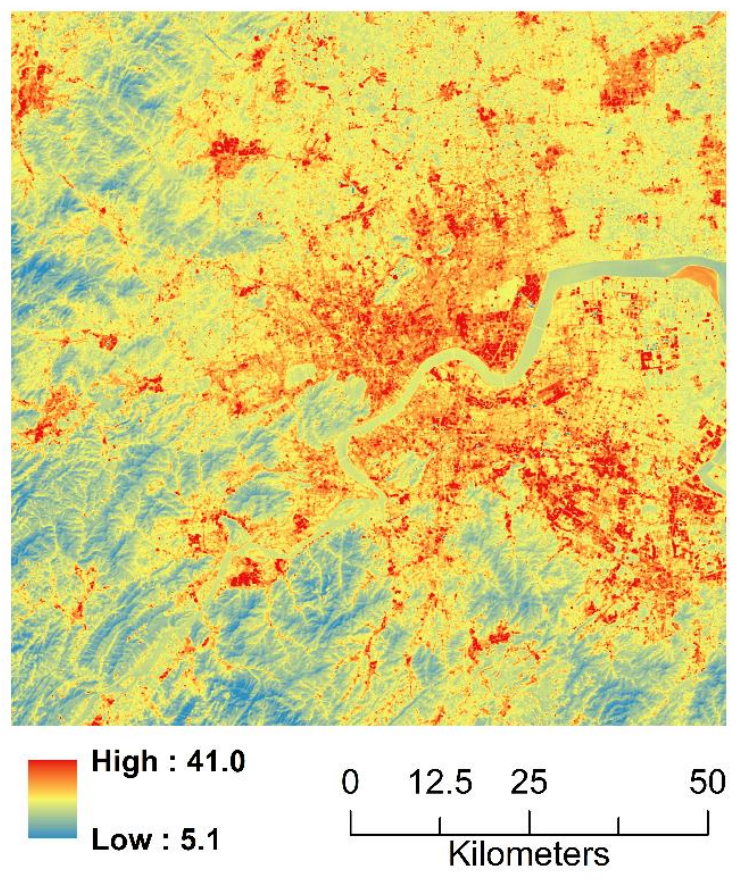

\section{Land Cover}
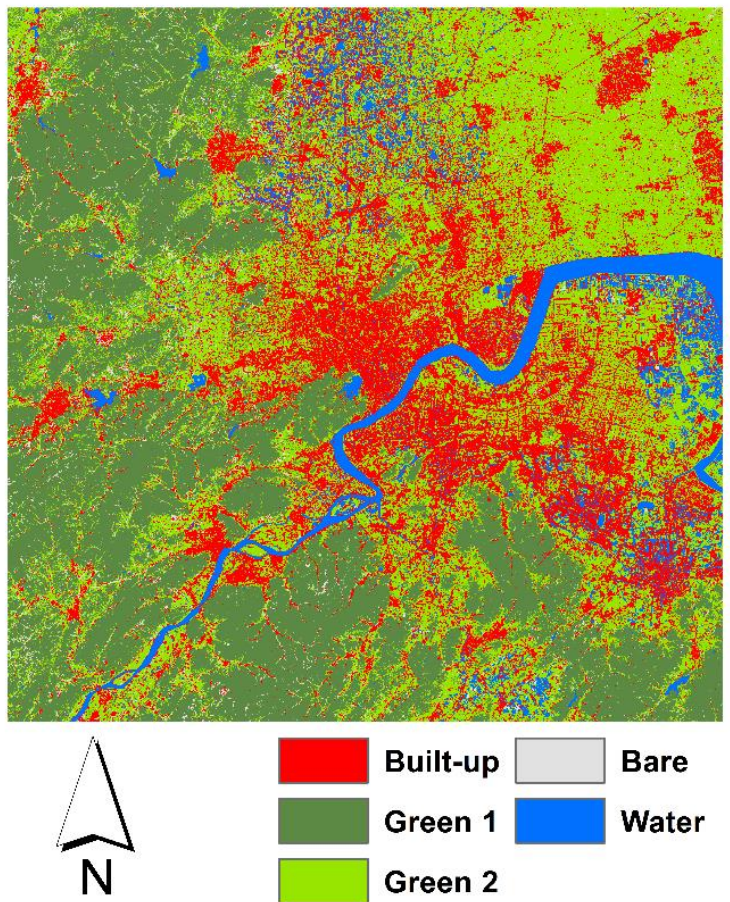

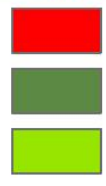

Built-up

Green 1

Green 2

Figure 1. The LST and land cover maps of Hangzhou 2:31 GMT (local time $+8 \mathrm{~h}$ ), 13th of October 2015.
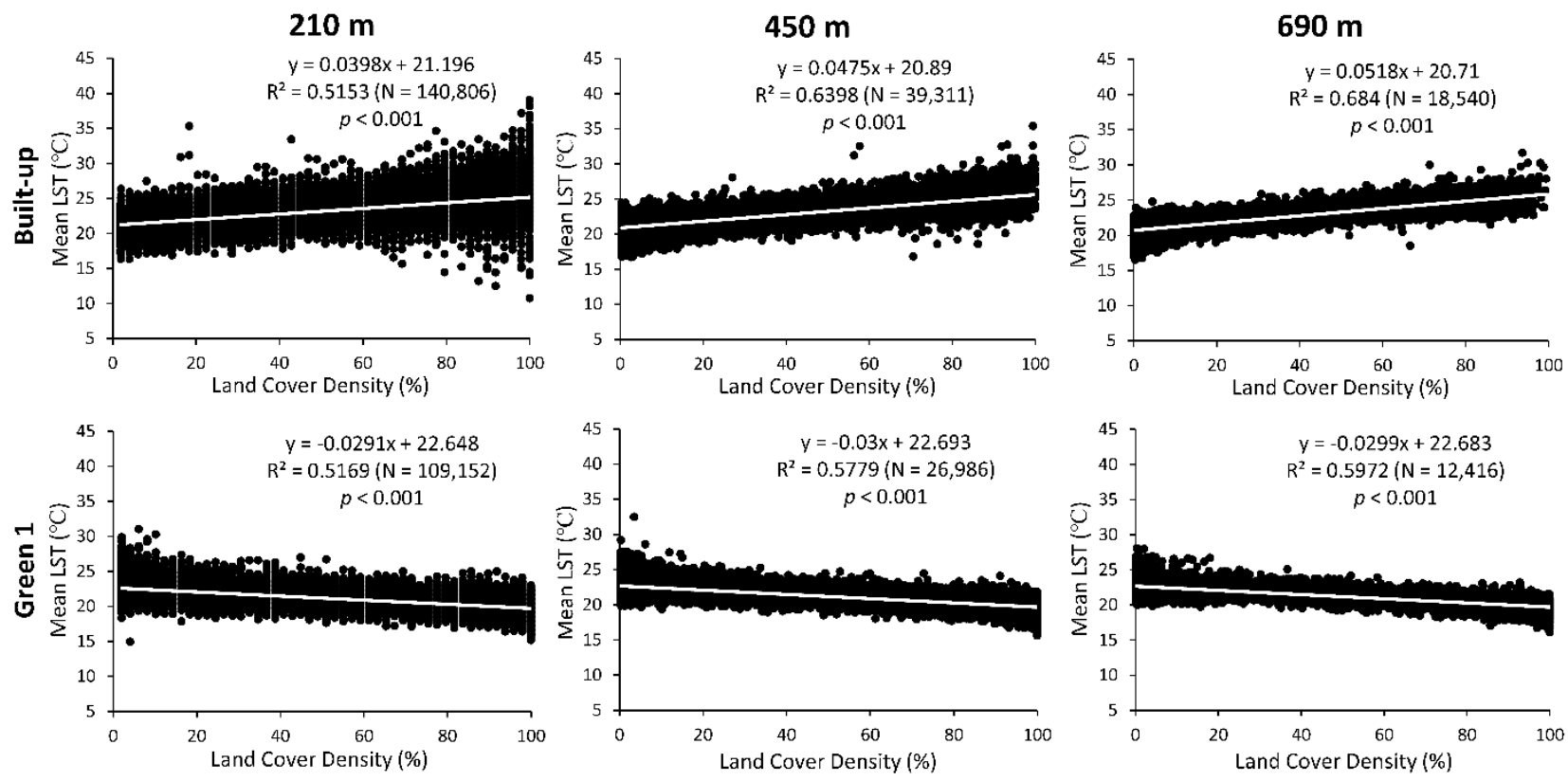

Figure 2. The scatter plots between land cover density and mean LST in polygon grids of $210 \mathrm{~m}, 450 \mathrm{~m}$, and $690 \mathrm{~m}$. 